\title{
Estratégias de aprendizagem de alemão como língua estrangeira na coleção de livros didáticos Studio [21]
}

\author{
Milena Hoffmann Kunrath ${ }^{1}$ \\ Bernardo Kolling Limberger ${ }^{2}$ \\ Centro de Letras e Comunicação, Universidade Federal de Pelotas, Pelotas, RS, Brasil
}

Resumo: Estratégias de aprendizagem podem ser definidas, segundo Oxford (1990), como ferramentas para o envolvimento ativo e autodirigido do estudante no seu processo de aprendizagem. Tais ferramentas são essenciais para o desenvolvimento da competência comunicativa e da autonomia na aprendizagem da língua estrangeira. Nesse sentido, o objetivo deste estudo é investigar como são abordadas as estratégias de aprendizagem na coleção de livros didáticos de alemão como língua estrangeira (DaF) Studio [21] e se a coleção bem desenvolve o que propõe sobre essas ferramentas. A coleção foi escolhida para analisá-la criticamente sob o viés da promoção da autonomia dos nossos estudantes e porque a adotamos nas nossas aulas de alemão como língua estrangeira. As estratégias são analisadas quantitativamente, por meio da contagem das ocorrências de apresentação das estratégias e de atividades correspondentes, e qualitativamente, por meio da análise de alguns excertos selecionados do livro e dos tipos de estratégias de aprendizagem enfatizadas. Os resultados mostram que um dos pilares da coleção é a apresentação de estratégias de aprendizagem, pois há várias ocorrências ao longo de toda a coleção. Entretanto, há predomínio de estratégias diretas (de memorização e cognitivas), em detrimento das estratégias indiretas, aquelas que não têm relação direta com a língua-alvo. Acreditamos que a contribuição deste estudo esteja situada na reflexão sobre as estratégias na aula de $D a F$ e no consequente aprimoramento e expansão do repertório e uso de estratégias por nossos alunos. Por extensão, o estudo pode contribuir para atingir os mesmos objetivos de outros professores.

Palavras-chave: Estratégias de aprendizagem; Alemão como língua estrangeira; Livro didático.

Title: Investigating the use of learning strategies in the series of German textbooks Studio [21]

Abstract: Learning strategies, according to Oxford (1990), can be defined as tools for active and selfdirected student engagement during the learning process. Such tools are essential for the development of communication skills and autonomy in foreign language learning. The goal of this study is to investigate the approach to learning strategies in the series of textbooks for German as a foreign language (DaF) Studio [21] and to verify whether the books achieve their proposed goals for these tools. The series of books was chosen for critical analysis in view of promoting student autonomy, and due to the fact that we make use of the series in the DaF classroom. Strategies were analyzed quantitatively by counting all instances

\footnotetext{
${ }^{1}$ Doutora em Letras pela Pontifícia Universidade Católica do Rio Grande do Sul. Professora do curso de Letras Português e Alemão da Universidade Federal de Pelotas. Orcid: https://orcid.org/00000002-3335-1152

E-mail: milena.kunrath@gmail.com

${ }^{2}$ Doutor em Letras pela Pontifícia Universidade Católica do Rio Grande do Sul. Professora do curso de Letras Português e Alemão da Universidade Federal de Pelotas. Orcid: https://orcid.org/0000-0001$\underline{5504-2361}$

E-mail: limberger.bernardo@gmail.com
} 
where learning strategies were presented, as well as related activities, and qualitatively by scrutinizing selected extracts and the strategies that were emphasized. Results show that the presentation of learning strategies is a focal point of the series, as there are multiple instances throughout the books. Nonetheless, direct strategies (memorization and cognitive strategies) are more preponderant than indirect ones, i.e. those which do not relate directly to the target language. We believe the contribution of the study lies in its discussion about the use of learning strategies in the context of the DaF classroom, as well as in the subsequent enhancement and expansion of our students' repertoire and use of strategies. Additionally, the study might assist other teachers in achieving the same goals. Keywords: Learning strategies; German as a Second Language; Text book.

\section{Introdução}

Um dos desafios do professor de qualquer disciplina é orientar os alunos para que eles aprendam a ser autônomos com relação a sua própria aprendizagem. Esse desafio se torna ainda maior devido às diferenças individuais entre os alunos. Por isso, é necessário que o professor prepare as suas aulas estando ciente da heterogeneidade, pois existem diversos caminhos que conduzem à aprendizagem, e nem todos os alunos precisam escolher o mesmo. Portanto, a partir de metodologias de trabalho adotadas pelo professor, cada estudante deve ser capaz de descobrir e selecionar as estratégias mais adequadas para aprimorar suas competências.

Estratégias de aprendizagem podem ser definidas, segundo Oxford (1990), como os passos dados pelos estudantes para melhorar o seu processo de aprendizagem. Elas são ferramentas para o envolvimento ativo e autodirigido, essenciais para o desenvolvimento da competência comunicativa. Em Oxford (2003), a autora acrescenta que, juntamente com os estilos de aprendizagem (global ou analítico, auditivo ou visual), as estratégias de aprendizagem estão entre os fatores principais que ajudam a determinar como e quão rápido os estudantes aprendem uma língua estrangeira.

Especificamente, as estratégias de aprendizagem, segundo uma lista de referências citadas por Vilaça (2010), podem contribuir para que os alunos aprendam como aprender línguas, desenvolvam a autonomia e a competência comunicativa, aprimorem habilidades metacognitivas e expandam os seus estilos de aprendizagem. Além disso, a descoberta e o uso de estratégias de aprendizagem pelos alunos respeitam as diferenças individuais na cognição (cf. reportadas por PRAT; JUST, 2008) e na experiência bilíngue/multilíngue (HERDINA; JESSNER, 2002), inerentes a qualquer turma de alunos.

Partindo dessas questões, este artigo tem relação com as preocupações sobre o desenvolvimento da autonomia e da competência comunicativa dos nossos estudantes de graduação Letras (português e alemão), que se preparam para se tornar professores de língua alemã. Nossas reflexões e análises podem ser pertinentes a outros profissionais que se envolvem com alemão como língua estrangeira (Deutsch als Fremdsprache - DaF), sejam eles professores, instrutores de línguas, coordenadores pedagógicos ou autores e editores de 
livros didáticos. Este estudo visa preencher uma lacuna na pesquisa em Linguística Aplicada brasileira, pois os estudos envolvendo estratégias de aprendizagem de DaF são bem mais recentes e escassos do que os que envolvem a aprendizagem de língua inglesa por exemplo (conforme PAIVA, 1996; VILAÇA, 2010).

O objetivo geral deste estudo é investigar como são abordadas as estratégias de aprendizagem em uma série de livros didáticos de DaF. Elegemos para a nossa reflexão sobre as estratégias de aprendizagem a coleção de livros didáticos Studio [21], desenvolvida por Christina Kuhn e Hermann Funk com seus colaboradores da editora Cornelsen. Adotamos essa coleção nas disciplinas de Língua Alemã da Universidade Federal de Pelotas (UFPEL) e visamos aprimorar e expandir, a partir desta reflexão, o repertório e o uso de estratégias por nossos alunos. Esse aprimoramento poderá ocorrer a partir da verificação de lacunas dos livros didáticos quanto aos tipos de estratégias. Os tipos de estratégias que estão em falta nos livros deverão ser abordados em sala de aula de modo complementar. As estratégias são analisadas quantitativamente, por meio da contagem das ocorrências de apresentação das estratégias e de atividades correspondentes, e qualitativamente, por meio da análise de alguns excertos selecionados do livro e os tipos de estratégias de aprendizagem enfatizadas (cf. OXFORD, 1990).

Este artigo está estruturado da seguinte forma: primeiramente, revisamos estudos sobre as estratégias de aprendizagem, com foco na língua estrangeira e em DaF. Em seguida, apresentamos o método aplicado a este trabalho, considerando os livros didáticos e os procedimentos de análise. Por fim, são apresentados os resultados qualitativos e quantitativos, bem como a discussão.

\section{Referencial teórico}

Nesta seção, revisamos estudos que embasam estratégias de aprendizagem em geral e, especificamente, com relação às línguas estrangeiras ${ }^{3}$. Em seguida, concentramo-nos em estudos sobre a abordagem das estratégias de aprendizagem de $D a F$, foco deste estudo.

Estratégias de aprendizagem de língua estrangeira

Aprender uma língua é um processo multifatorial, pois o nível de proficiência do estudante pode ser influenciado por múltiplos fatores. Por isso, há muitas diferenças individuais nos processos de aprendizagem de uma língua estrangeira. Além de fatores psicológicos, como motivação, inteligência, aptidão e personalidade (cf. PARADIS; GENESEE;

\footnotetext{
${ }^{3} \mathrm{O}$ uso do termo 'estrangeira' se relaciona à tradução de Deutsch als Fremdsprache, para se referir à aprendizagem de uma língua que ocorre, como explica Ellis (1994), exclusivamente em contexto escolar, em regiões nas quais a língua aprendida não é a língua principal da comunicação cotidiana.
} 
CRAGO, 2011), outros especificamente linguísticos também podem exercer influência sobre o nível de proficiência. Dentre esses fatores, podemos citar a interação e transferência entre as línguas, seu contexto de aprendizagem (se aprendidas em contexto primário ou secundário), sua ordem de aquisição e relação etimológica/tipológica, além da recência de aprendizagem, da perda linguística e do método de ensino e aprendizagem (HUFEISEN, 2003).

No que tange aos aspectos metodológicos que podem influenciar o resultado da aprendizagem, Hufeisen (2003) destaca as estratégias de aprendizagem. Esse tema tem sido objeto de investigação da Linguística Aplicada principalmente desde os anos 1970 (VILAÇA, 2010). Segundo esse autor, a linguista Rubin (1975) impulsionou o interesse pelo estudo das estratégias de aprendizagem. Esse trabalho seminal pode ser considerado um marco para a Linguística Aplicada, pois estipulou a importância da adoção de estratégias por um bom aprendiz de língua estrangeira. Estratégias de aprendizagem, segundo Oxford (1990), são

passos dados pelos estudantes para melhorar sua própria aprendizagem. As estratégias são especialmente importantes para a aprendizagem de línguas porque são ferramentas para um envolvimento ativo e autodirigido, essenciais para o desenvolvimento da competência comunicativa. Estratégias de aprendizagem de línguas usadas adequadamente resultam em uma melhor proficiência e autoconfiança. (OXFORD, 1990, p. 1) ${ }^{4}$

O termo 'estratégia', conforme a autora, deriva do vocábulo strategia no grego antigo, que denota habilidade militar ou a arte da guerra. As estratégias envolviam, então, a administração de tropas, navios ou forças aéreas. A palavra 'estratégia' implicava planejamento, competição, manipulação consciente e movimento em direção a um objetivo. Por extensão, o conceito de estratégia tem sido aplicado a situações em que há um plano, passo ou uma ação consciente para atingir um objetivo. Na aprendizagem, estratégias seriam procedimentos conscientes aplicados na compreensão e na produção linguística, como, por exemplo, a utilização de regras gramaticais do inglês para a compreensão leitora em alemão (PEYER; KAISER; BERTHELE, 2010). Cenoz (2013) acrescenta como exemplo a utilização de técnicas para a memorização de vocabulário.

As estratégias podem ser transferidas, conforme Hufeisen (2003), da aprendizagem de uma língua para a outra, de modo que, com cada língua aprendida, o aprendiz expanda o seu repertório de estratégias de aprendizagem de língua estrangeira. Devido ao repertório mais vasto de estratégias de aprendizagem que o bilíngue possui, o próprio bilinguismo ${ }^{5}$ pode exercer potencial influência sobre a aprendizagem das línguas seguintes (CENOZ, 2013), pois

\footnotetext{
${ }^{4}$ No original: "Learning strategies are steps taken by students to enhance their own learning. Strategies are especially important for language learning because they are tools for active, selfdirected involvement, which is essential for developing communicative competence. Appropriate language learning result in improved proficiency and greater self-confidence."

${ }^{5}$ Bilinguismo, neste trabalho, é entendido em seu sentido amplo (cf. GROSJEAN, 2010), ou seja, contempla todos os falantes que usam duas ou mais línguas (ou dialetos) nas suas vidas cotidianas.
} 
esses aprendizes possuem mais experiência linguística e uma consciência metalinguística mais desenvolvida do que aprendizes de uma L2.

A taxonomia de Oxford (1990, p. 17) para as estratégias de aprendizagem ainda é uma obra de referência. Conforme Vilaça (2010), a autora combina discussão teórica e orientações para a prática em sala de aula e disponibiliza o maior repertório de estratégias. Oxford (1990) divide as estratégias em dois grupos: (a) estratégias diretas e (b) indiretas. Cada um dos grupos se subdivide em três tipos de estratégias. As estratégias diretas (de memória, cognitivas e de compensação) requerem processamento na língua-alvo. As estratégias de memória têm a função específica de auxiliar os estudantes a armazenar e acessar as informações novas; as cognitivas permitem que os estudantes compreendam e produzam a língua-alvo de diferentes formas, isto é, que exercitem a habilidade de usar a língua; e as estratégias de compensação auxiliam os estudantes na produção, mesmo com lacunas de conhecimento.

Por outro lado, as estratégias indiretas (metacognitivas, afetivas e sociais) sustentam e influenciam a aprendizagem, não tendo relação com os elementos propriamente linguísticos. As estratégias metacognitivas permitem que os aprendizes controlem a sua própria cognição, coordenando o processo de aprendizagem. Elas ajudam os estudantes a regularem as emoções, a motivação e as atitudes; e as sociais os auxiliam por meio da interação com os outros. No esquema abaixo, apresentamos as estratégias em detalhes de acordo com Oxford (1990):

\section{a) Estratégias diretas:}

i) de memorização:

1) criar relações mentais - agrupar informações em unidades de significado; associar/elaborar informações conhecidas e novas; colocar novas palavras em contexto;

2) usar imagens e sons - relacionar imagens a conceitos; fazer mind maps; memorizar palavras por meio de relações auditivas e visuais com as línguas conhecidas; memorizar informações linguísticas de acordo com as suas características fonológicas (p. ex., usar rima para se lembrar de uma palavra);

3) revisar - usar uma estrutura para revisar, ou seja, com repetições espaçadas;

4) empregar ações - movimentar-se para memorizar palavras/ expressões ou relacioná-las a sentimentos ou sensações; usar técnicas cinestésicas (p. ex., mover cartelas de palavras de um lugar para outro);

ii) cognitivas:

1) exercitar - repetir e ensaiar segmentos linguísticos; praticar a relação de grafema e fonema; reconhecer e usar fórmulas, chunks e padrões; combinar elementos novos com conhecimentos prévios; usar a língua em contexto natural; 
2) receber e enviar mensagens - obter as ideias principais de um texto rapidamente; usar recursos audiovisuais para compreender ou produzir mensagens;

3) analisar e raciocinar - raciocinar dedutivamente; analisar expressões e frases decompondo-as em partes; comparar línguas; traduzir para compreender; transferir elementos de uma língua para compreender ou produzir a outra;

4) criar estruturas para input e output - tomar notas sobre pontos específicos ou ideias principais; resumir; usar técnicas de realçar informações importantes;

iii) de compensação:

1) adivinhar inteligentemente, por meio de inferências - usar pistas linguísticas (p. ex., morfemas); usar pistas não linguísticas (p. ex., conhecimento de mundo e elementos gráficos);

2) superar limitações em falar e escrever - recorrer à L1; pedir ajuda sobre a expressão desconhecida na língua-alvo; usar mímica ou gestos; evitar total ou parcialmente a comunicação, devido a lacunas linguísticas; selecionar um tópico relacionado a um campo lexical conhecido; ajustar ou aproximar a mensagem dos seus conhecimentos; criar palavras e expressões; usar perífrases ou sinônimos;

\section{b) Estratégias indiretas:}

i) metacognitivas:

1) centrar a aprendizagem - sistematizar e relacionar o conteúdo a conhecimentos prévios; prestar atenção a aspectos específicos e ignorar distratores; adiar a produção oral para focar na compreensão auditiva e aprimorar as habilidades;

2) organizar e planejar a aprendizagem - fazer descobertas sobre a aprendizagem de línguas e usar essas informações para aperfeiçoar a aprendizagem; organizar cronograma, cadernos e espaço de aprendizagem; estabelecer metas e objetivos para a aprendizagem; identificar o propósito de uma tarefa linguística; fazer o planejamento para cumprir determinada tarefa; tentar conseguir oportunidades de usar a língua em contextos naturais;

3) avaliar a aprendizagem - monitorar os próprios erros; avaliar o próprio progresso de aprendizagem;

ii) afetivas:

1) diminuir a ansiedade - relaxar, respirar profundamente ou meditar; escutar música para relaxar; manter-se bem-humorado;

2) encorajar-se - fazer declarações positivas para si mesmo; assumir riscos sabiamente; recompensar-se em caso de sucesso; 
3) atentar à condição emocional - prestar atenção aos sinais do corpo, como estresse; usar uma check list para tarefas, sentimentos e atitudes; escrever um diário de aprendizagem; conversar com alguém sobre os sentimentos relacionados à aprendizagem;

iii) sociais:

1) fazer perguntas - pedir para o interlocutor ajudar na compreensão dos enunciados, por meio de, por exemplo, repetições e explicações; pedir por correção na produção;

2) trabalhar com outros - trabalhar com os pares para aprimorar habilidades; conversar com falantes proficientes da língua-alvo;

3) ter empatia com os outros - desenvolver o entendimento da cultura da língua-alvo; tornar-se consciente dos pensamentos e sentimentos dos outros por meio de observação.

A classificação de Oxford (1990) das estratégias de aprendizagem segue critérios atrelados a sua relação com a língua estrangeira - direta ou indireta. Nas estratégias indiretas se encaixam as metacognitivas. Entretanto, o uso de estratégias sempre requer que o estudante reflita sobre os seus processos mentais. Por isso, podemos dizer que a relação entre as estratégias e a metacognição é estreita. Metacognição pode ser definida, segundo Flavell (1979), como o conhecimento consciente que a pessoa possui acerca de seus processos cognitivos. Essa capacidade envolve monitorar a sua própria memória, a compreensão e outros processos cognitivos, como a aprendizagem formal. Então, podemos dizer que o construto psicológico da metacognição é usado em qualquer estratégia de aprendizagem, pois é necessário que o indivíduo esteja consciente dos seus processos mentais.

\section{Abordagem das estratégias de aprendizagem de DaF}

Na aula de língua estrangeira, conforme Oxford (1990), as estratégias, depois de certa quantidade de prática de uso, como qualquer habilidade, podem se tornar automáticas. Um ensino voltado também para o desenvolvimento de estratégias pode auxiliar os estudantes a se tornarem mais conscientes sobre como eles aprendem e a avaliar a utilidade das estratégias. $O$ treino de estratégias pode ser mais efetivo quando os estudantes aprendem por que e quando as estratégias são importantes, como usar as estratégias e como transferilas para novas situações. A abordagem do professor, por meio do trabalho em sala de aula (apresentação, experimentação e teste de diferentes estratégias), deve ajudar cada estudante a ganhar autoconfiança com relação a como ele aprende, bem como desenvolver meios de potencializar as suas experiências de aprendizagem.

Então, cada aluno pode tentar descobrir as estratégias de aprendizagem mais apropriadas para si, especificamente de $D a F$, mais adequadas para si. Essa descoberta, 
vinculada ao ensino, também é incentivada pelo Quadro Europeu Comum de Referência para Línguas - QECRL - (CONSELHO DA EUROPA, 2005), que baseia a formulação dos livros didáticos concebidos na Europa. Ao longo da aprendizagem, espera-se, segundo o documento, que os estudantes desenvolvam suas capacidades de estudo e aceitem a responsabilidade pela sua própria aprendizagem. Para tanto, almeja-se que eles "identifiquem o seu próprio estilo cognitivo e desenvolvam, consequentemente, as suas próprias estratégias de aprendizagem" (CONSELHO DA EUROPA, 2005, p. 208).

Conforme Glaboniat et al. (2005), que analisam o QECRL, para o desenvolvimento das estratégias, há várias técnicas disponíveis. O professor deve oferecer instrução sobre as estratégias, que variam de acordo com o indivíduo, a personalidade, a competência linguística, entre outros fatores. Os autores aconselham que a aprendizagem seja organizada em etapas, isto é, antes, durante e depois da tarefa. O documento enfatiza o uso de estratégias com uma forma de desenvolvimento da autonomia.

A aprendizagem autônoma pode ser caracterizada, segundo Bimmel e Rampillon (2004), pela tomada de decisões pelos próprios estudantes sobre a sua aprendizagem. Eles podem decidir, por exemplo, o que, como, com que material, em quanto tempo eles aprendem determinado conteúdo. No que se refere ao "como", os autores defendem que os estudantes necessitam aprender a aprender a língua estrangeira, e as estratégias são os requisitos para que isso aconteça. Além disso, conforme os mesmos autores, o ensino de estratégias também pode contribuir para que cada estudante se sinta representado na aula. Um livro didático e uma abordagem comunicativa não dão conta dessas tarefas; por isso, como argumenta Ten Kathen (2016), as estratégias podem ser um importante recurso para promover a diferenciação (Binnendifferenzierung) em grupos extremamente heterogêneos. É evidente que as estratégias não garantem automaticamente a aprendizagem mais autônoma, mas podem contribuir para desenvolver essas habilidades, como argumentam estudos brasileiros sobre estratégias de aprendizagem de DaF (CARVALHO, 2016; STANKE, 2008; TEN KATHEN, 2016).

Nesses estudos, essas pesquisadoras testaram a eficácia das estratégias de aprendizagem na aula de DaF em contextos escolares (CARVALHO, 2016; TEN KATHEN, 2016) e universitários, isto é, de ensino de alemão para fins específicos - alemão instrumental (STANKE, 2008). De forma geral, as autoras buscaram investigar de que modo o uso de estratégias de aprendizagem pode contribuir para que os estudantes de cada um dos contextos analisados se tornassem mais autônomos. Por meio de questionários aplicados após a instrução sobre estratégias de aprendizagem, Ten Kathen (2016) verificou que os alunos perceberam a utilidade das estratégias e as usaram no seu cotidiano escolar, sentindose mais responsáveis pela própria aprendizagem. Com um método semelhante, Carvalho (2016) identificou benefícios da intervenção sobre estratégias de aprendizagem especificamente na produção textual de alunos de uma turma multisseriada de língua alemã. Os resultados de Stanke (2008) vão ao encontro dos benefícios das estratégias de aprendizagem para o desenvolvimento da autonomia. A autora destaca o papel de conhecer 
a gama de estratégias que podem ser utilizadas especificamente na leitura e de se conscientizar sobre o papel específico da leitura em língua alemã na sociedade.

De interesse especial para este estudo é o trabalho de Cunha (2013), que analisou atividades dos livros da coleção Studio $d$, o antecessor da coleção Studio [21]. Um dos objetivos do autor foi investigar se as estratégias de aprendizagem condizem com as propostas de Bimmel e Rampillon (2000), que sugerem exercícios de estratégias de aprendizagem de alemão com base em Oxford (1990). Após a análise das estratégias presentes em três lições, o autor identificou estratégias principalmente cognitivas e, em menor número, estratégias afetivas e sociais. Além disso, segundo o autor, as lições possibilitam a integração dos exercícios com o ensino de estratégias.

Cientes da importância das estratégias de aprendizagem de língua estrangeira para o desenvolvimento da autonomia e da competência linguística, visamos verificar como essas estratégias são apresentadas e abordadas na coleção Studio [21]. A seguir, apresentamos o método referente do nosso estudo.

\section{Método}

Apresentamos, nesta seção, a justificativa para a escolha da coleção de livros, bem como a análise, que é, por um lado, de cunho quantitativo e, por outro, de cunho qualitativo. Quantificamos as ocorrências de apresentação das estratégias e de atividades correspondentes, a fim de estabelecer uma visão panorâmica dessa abordagem. De forma complementar, por meio da análise qualitativa, analisamos alguns excertos selecionados dos livros e os tipos de estratégias de aprendizagem enfatizadas.

\section{Livros didáticos selecionados}

A coleção de livros Studio [21] $]^{6}$, desenvolvida por Christina Kuhn e Hermann Funk com seus colaboradores da editora Cornelsen, é analisada por ter sido adotada nas disciplinas de Língua Alemã da Universidade Federal de Pelotas (UFPEL), o que conduz à necessidade de avaliarmos e, possivelmente, expandirmos o repertório de estratégias de aprendizagem disponibilizado pela coleção. Logo, no caso de detectarmos carência na oferta de algum tipo de estratégia, tornar-se-ia possível complementar a abordagem.

\footnotetext{
${ }^{6}$ Para mais informações: https://www.cornelsen.de/studio 21/. Acesso em 25 jan. 2019.
} 
A seleção dessa coleção para análise se justifica pela intenção de aprimorarmos e expandirmos o repertório de estratégias de aprendizagem dos nossos alunos ${ }^{7}$. Então, em caso de carência na oferta de algum tipo de estratégias, seria necessário complementar a abordagem. Segundo Oxford (1990), por meio das estratégias, os estudantes podem aprimorar e ganhar autoconfiança nos processos de aprendizagem, bem como podem desenvolver meios para potencializar as suas experiências de aprendizagem.

Os livros pertencentes à coleção Studio [21] são atuais, pois são desenvolvidos com um design moderno, e possuem fotos e ilustrações contemporâneas. Os materiais são uma reedição revista e ampliada de uma coleção antiga (Studio d) e se destinam, segundo Funk et al. (2016), a adultos sem conhecimentos prévios de língua alemã, para aprendizagem dentro ou fora da Alemanha. A coleção é composta por livros didáticos e materiais online correspondentes aos níveis A1-B1 do Quadro Europeu Comum de Referência para Línguas (CONSELHO DA EUROPA, 2005). Ao pacote, pertencem os seguintes materiais, que podem ser adquiridos: livro didático impresso e em formato de e-book (livro-curso e livro de exercícios), DVD com vídeos didáticos, CD com áudios, livro com orientações sobre planejamento, gerador de folhas de exercícios, livros com provas, exercícios online, exercícios adicionais (Intensivtraining), aplicativo para treino de vocabulário, plataforma de discussão no Moodle, caderno de vocabulário, folhas de exercícios para download grátis e glossários bilíngues.

Conforme Funk et al. (2016), o livro se destaca por: ter textos e temas motivadores; possibilitar aprendizagem por meio de tarefas que tornam os estudantes ativos; abordar a compreensão auditiva e o treino fonético; oferecer uma abordagem de vocabulário sistemática; dar instruções para o cotidiano e para o trabalho; basear-se na perspectiva intercultural e ofertar modelos de provas de proficiência. Os seguintes princípios didáticos caracterizam o trabalho com o livro didático Studio [21]:

a) exercícios nos quais a compreensão, o uso e a automatização de formas linguísticas desempenham um papel crucial;

b) sequências de aprendizagem sem separação artificial das quatro habilidades;

c) abordagem gramatical orientada por fórmulas de rotina, descoberta de regras e exercícios comunicativos realistas;

d) trabalho com fonética integrado e continuado até o nível B1;

e) oferta de mídias para serem utilizadas de forma flexível e opcional;

f) trabalho com Landeskunde atual (cultura e civilização germanófona) e abordagem intercultural;

g) oferta de textos suplementares (compreensão leitora e auditiva);

h) abordagem orientada a provas de proficiência;

i) trabalho com léxico voltado às relações entre as palavras;

\footnotetext{
${ }^{7}$ Este artigo se insere no projeto de pesquisa Formas de Aprimoramento da Língua Alemã: criação de estratégias de aprendizagem pelos alunos, coordenado pela professora Dra. Milena Hoffmann Kunrath na UFPEL.
} 
j) dicas de aprendizagem que fomentam o desenvolvimento de estratégias de aprendizagem individuais.

No que tange especificamente ao último ponto, Funk et al. (2016) explicam, no livro de preparação de aulas, que cada unidade possui uma série de considerações e dicas para o treinamento sistemático de estratégias de aprendizagem. Os autores tentam apresentar comentários que são integrados à temática e à ação comunicativa de cada unidade. Isso oferece ao estudante a possibilidade de conhecer estratégias e descobrir um caminho de aprendizagem mais eficiente para si. Segundo os autores, há treinamento explícito (apresentação de Lerntipps 'dicas de aprendizagem') e implícito (integrado a exercícios).

\section{Procedimentos de análise}

Analisamos os livros didáticos completos de cada um dos três níveis, isto é, os livroscurso e os livros de exercícios. Quantificamos as ocorrências de apresentação e de atividades de estratégias de aprendizagem. Depois de pronta primeira quantificação, discutimos a análise. Então, cada uma das atividades das doze lições dos livros A1 e A2 e das dez lições do livro B1 foi analisada, bem como as atividades das quatro Stationen (bloco de revisão ao fim de cada quatro lições) nos livros A1 e A2, e nas duas Stationen (ao fim de cada 5 lições) no livro B1. Em seguida, as ocorrências encontradas foram analisadas de acordo com a taxonomia das estratégias de aprendizagem de língua de Oxford (1990): estratégias diretas (de memória, cognitivas e de compensação) e estratégias indiretas (metacognitivas, afetivas e sociais). Dessa forma, visamos oferecer um panorama da abordagem das estratégias de aprendizagem em uma coleção de livro didático para adultos.

As atividades e/ou sugestões de estratégias apresentadas nos livros didáticos foram incluídas no corpus do estudo e foram analisadas qualitativamente, a fim de verificar como são abordadas diferentes estratégias. Apresentamos, neste artigo, alguns exemplos dessa abordagem.

\section{Resultados e discussão}

Nos três livros didáticos da coleção Studio [21] (níveis A1 a B1), encontramos a oferta de múltiplas estratégias de aprendizagem. Essas estratégias podem ou não ser abordadas pelos professores e, mesmo que elas sejam trabalhadas em sala de aula, o aluno pode optar por não as adotar. Na tabela 1, apresentamos a quantidade de ocorrências das estratégias de aprendizagem de acordo com as categorias disponíveis nos livros didáticos, ou seja, dicas de aprendizagem, Minimemos 'minilembretes', sistematização, autoavaliação, Redemittel (estruturas para a produção oral) e estruturas para a produção escrita. 
Tabela 1 - Quantidade de ocorrências de estratégias de aprendizagem na coleção Studio [21]

\begin{tabular}{|c|c|c|c|c|c|c|}
\hline \multirow[t]{2}{*}{$\begin{array}{c}\text { Tipo de } \\
\text { ocorrência }\end{array}$} & \multicolumn{3}{|c|}{$\begin{array}{l}\text { Número de } \\
\text { ocorrências }\end{array}$} & \multicolumn{3}{|c|}{ Páginas } \\
\hline & $\mathrm{A} 1$ & $\mathrm{~A} 2$ & B1 & $\mathrm{A} 1$ & $\mathrm{~A} 2$ & B1 \\
\hline $\begin{array}{l}1 \text { Dica de } \\
\text { aprendizagem }\end{array}$ & 14 & 14 & 15 & $\begin{array}{l}14,34(2 x), 35,79 \\
(5 x), 150,188,189 \\
(2 x), 255\end{array}$ & $\begin{array}{l}32,148,163,187 \\
253,254,257(2 x) \\
259(2 x), 260(2 x) \\
261\end{array}$ & $\begin{array}{l}36,52,129,169 \\
171,190,236 \\
(2 x), 238,239 \\
(2 x), 241(3 x), 242\end{array}$ \\
\hline 2 Minimemos & 18 & 7 & 6 & $\begin{array}{l}18,19,20,49,92, \\
94,95,111,112, \\
132,151,165,167, \\
169,188,190,208, \\
236\end{array}$ & $\begin{array}{l}36,41,64,129,163 \\
201,259\end{array}$ & $\begin{array}{l}40,89,151,190 \\
232,238\end{array}$ \\
\hline 3 Sistematização & 2 & 1 & 2 & 34,79 & 163 & 18,197 \\
\hline 4 Autoavalição & 13 & 13 & 13 & $\begin{array}{l}31,47,63,89,105 \\
121,125,145,161 \\
177,201,217,233\end{array}$ & $\begin{array}{l}29,45,61,85,101 \\
117,141,157,163 \\
173,197,213,229\end{array}$ & $\begin{array}{l}29,45,61,85 \\
101,117,141 \\
157,173,197 \\
207,213,229\end{array}$ \\
\hline $\begin{array}{l}5 \text { Produção oral: } \\
\text { Redemittel }\end{array}$ & 20 & 26 & 23 & $\begin{array}{l}17,19,23,32,37 \\
49,55,73,77,90 \\
97,109,131 \\
149,163,189,192 \\
203,204,221\end{array}$ & $\begin{array}{l}8,10,17,31,32,46, \\
49,72,75,89,93, \\
103,105,108,119, \\
129,130,142,145, \\
147,159,165,183, \\
199,203,215\end{array}$ & $\begin{array}{l}8,11,12,14,17, \\
31,33,48,50,55, \\
66,72,87,90,91, \\
102,113,130, \\
137,152,154, \\
188,189\end{array}$ \\
\hline $\begin{array}{l}6 \text { Estruturas para } \\
\text { a produção } \\
\text { escrita }\end{array}$ & 1 & - & 9 & 153 & - & $\begin{array}{l}10,18,36,70 \\
114,131,149 \\
155,167\end{array}$ \\
\hline
\end{tabular}

A seguir, analisamos cada um dos tipos de estratégias de aprendizagem oferecidas pelos livros didáticos da coleção, conforme a tabela acima. Além disso, apresentamos exemplos das ocorrências encontradas, que são discutidos à luz da taxonomia de Oxford (1990) e do referencial teórico complementar. 
Dica de aprendizagem (Lerntipp)

"Dica de aprendizagem", tradução de Lerntipp são quadros padronizados (como vemos na figura 1) com sugestões simples que indicam a forma mais adequada (que já foi testada e obteve mais sucesso) de memorizar informações, resolver uma questão, entender um ponto gramatical etc. A apresentação de dicas e as atividades correspondentes, correspondem ao que os próprios autores denominam de treinamento explícito (FUNK et al., 2016). Para este item, separamos as ocorrências de dicas de acordo com os livros e classificamos cada ocorrência individualmente.

Dicas de aprendizagem em Studio [21] A1 (FUNK; KUHN, 2013)

As dicas aparecem com uma gradação, das mais fáceis para as mais complexas. Observamos que, nos primeiros capítulos dos livros, as Lerntipps abarcam, proporcionalmente, conteúdos inicialmente aprendidos, sempre de forma simples. Porém, com o desenvolvimento dos temas, as dicas contemplam aspectos mais complexos da língua alemã. Ainda assim, aquelas dicas aprendidas no início do processo de estudo da língua ainda são válidas em etapas mais avançadas.

Figura 1 - Primeira dica de aprendizagem do livro Studio [21] A1

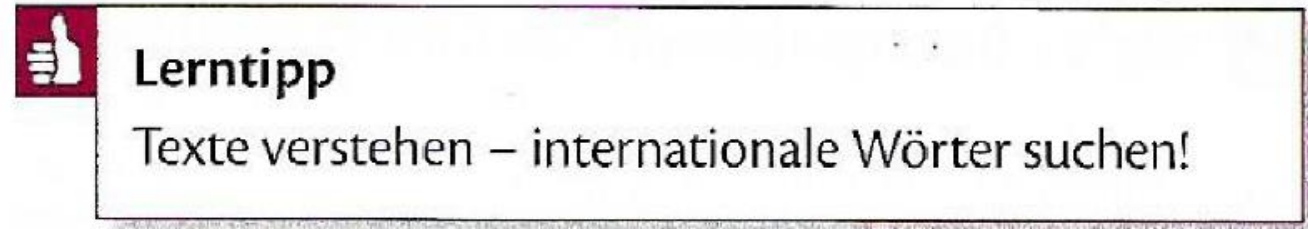

Fonte: Funk e Kuhn (2013, p. 14)

A primeira dica, apresentada já no início do livro A1, sugere que, para compreender um texto, é necessário procurar por palavras cognatas nas línguas ocidentais. Tal instrução se presta aos textos mais simples, e, posteriormente, aos mais complexos. Pela classificação de Oxford (1990), este seria um exemplo de uma estratégia direta (a), cognitiva (ii), de análise e raciocínio (3), pois envolve transferir elementos de uma língua para compreender a outra. A habilidade enfatizada é a compreensão leitora, mas essa estratégia pode ser expandida para a compreensão auditiva. Essa dica é fundamental para que essa estratégia seja aplicada sempre que possível, porque ela potencializa a aprendizagem e, segundo Hufeisen e Marx

\footnotetext{
${ }^{8}$ Tradução da Figura 1:

Dica de aprendizagem:

Compreensão de textos - buscar palavras internacionais!
} 
(2007), possibilita o multilinguismo receptivo, por meio da comparação especificamente entre as línguas germânicas.

As dicas apresentadas em seguida no livro didático A1 (p. 34) aparecem em conjunto com outras: a primeira sugere que os substantivos em alemão sejam sempre memorizados com seus respectivos artigos. Trata-se de uma estratégia direta (a), de memorização (i) de criação de relações mentais (1), agrupando informações em unidades de significado, no caso, sintagmas. Já a segunda estratégia apresentada nessa mesma página mostra uma maneira de como facilitar a memorização de artigos, relacionando imagens de palavras que possuem o mesmo gênero, ou seja, criando uma narrativa na mente (estratégia direta (a), de memória (i) de uso de imagens e sons para relacionar conceitos (2). Essa técnica é bastante difundida, inclusive entre leigos ${ }^{9}$, e pressupõe a formação de associações entre conceitos, o que facilita a retenção de informações. Isso ocorre porque a nossa memorização é estimulada por informações provindas de vários canais sensoriais (MACEDONIA, 2013). No caso, são relacionadas informações que possibilitam uma ativação de mais áreas do cérebro, devido à conjunção entre imaginação, sistema visual e linguagem.

Figura 2 - Dicas de aprendizagem de palavras e o respectivo gênero

3 Artikel-Lerntipps. Lesen Sie und probieren Sie die Lerntipps aus.

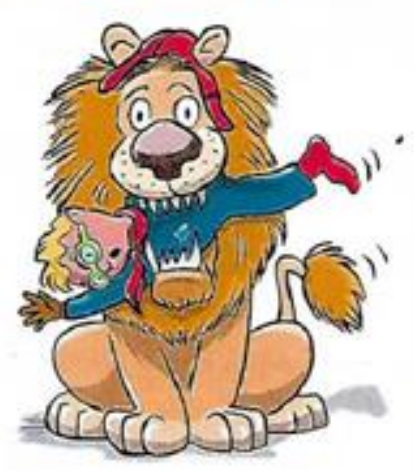

der Löwe der Pilot

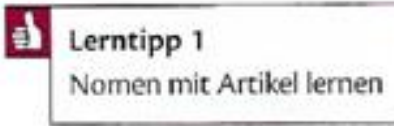

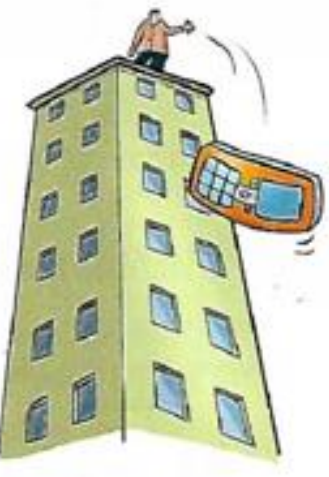

das Haus das Handy

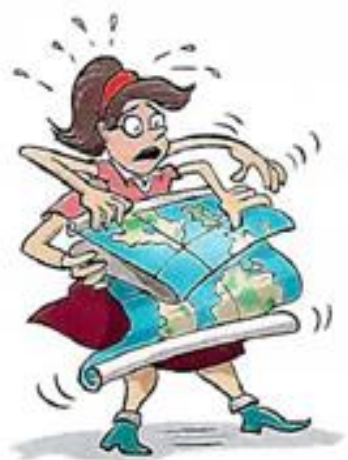

die Lehrerin die Landkarte

Al Lerntipp 2

Wörter und Bilder verbinden, „Artikelgeschichten" ausdenken: ein Film im Kopf

Fonte: Funk e Kuhn (2013, p. 34) ${ }^{10}$

9 Ver, por exemplo, a página da revista Superinteressante: https://super.abril.com.br/ideias/8tecnicas- matadoras-para-memorizar-qualquer-coisa/. Acesso em 20 fev. 2019.

${ }^{10}$ Tradução da Figura 2:

3 Artigos - Dicas de aprendizagem. Leia e exercite a dica de aprendizagem.

o leão

o piloto

a casa (neutro)

o celular (neutro)

Dica de aprendizagem 1

Estudar os substantivos com artigos
Dica de aprendizagem 2
a professora
o mapa (feminino)

Combinar palavras e figuras, pensar em histórias com os artigos: um filme na cabeça 
Além da apresentação dessas estratégias, são sugeridas no livro do professor (Funk et al., 2013, p. 37) alternativas para a memorização de palavras e do respectivo gênero. A primeira é o uso de cores para memorizar o gênero e o número das palavras (azul = masculino; verde $=$ neutro; vermelho $=$ feminino; amarelo $=$ plural). A outra estratégia sugerida é movimentar-se para memorizar palavras e o gênero. Os autores sugerem que os alunos se movimentem para uma direção (por exemplo, esquerda), se a palavra ouvida/lida é masculina e assim sucessivamente. Essa estratégia pode ser classificada como estratégia direta (a), de memorização (i) de criação de relações mentais (1) empregar ações.

Já no primeiro livro da coleção, os autores parecem ter a preocupação de apresentar estratégias de memorização que podem acompanhar os estudantes em todo o processo de aprendizagem, do nível A1 até o B1. Na página 35, por exemplo, da mesma ordem na estratégia anterior (figura 2), sugere-se a memorização das formas plurais juntamente com a aprendizagem da forma singular. Da mesma forma, na página 79 , aparece um novo conjunto de cinco dicas em relação à memorização de vocabulário com alguns exemplos práticos de como fazê-lo (colar notas com os vocábulos nos objetos que os representam, criar redes de palavras, preparar cartelas com informações sobre as palavras, criar chunks ou Redemittel (frases prontas)com as palavras-alvo, estudar as palavras em pares): são estratégias diretas (a), de memorização (i), da ordem de criação de relações mentais (1), de uso de imagens e sons para relacionar conceitos (2), e de revisão (3). Trata-se de um conjunto de estratégias de aprendizagem de vocabulário relacionado à mobília que podem ser selecionadas e aplicadas pelos alunos para a aprendizagem de palavras relacionadas a qualquer campo semântico. Para complementar as estratégias básicas de memorização de vocabulário, na página 150, a estratégia sugerida para memorização é simplesmente a repetição, mas que é efetiva, especialmente nos casos de repetições espaçadas. Dicas de memorização de vocabulário como essas são reiteradas na página 189, relacionadas ao léxico de alimentação, para reforço e aprendizagem sistemática (Wortschatz systematisch). O livro expande um pouco as dicas, sugerindo que as palavras sejam memorizadas juntamente com a sua pronúncia. Essa prática configura uma estratégia cognitiva (ii), de exercício (1). Dessa forma, os estudantes podem ensaiar segmentos linguísticos e praticar a relação grafema-fonema entre das palavras.

Além da apresentação de estratégias diretas, há uma ocorrência (p. 188) de estratégia indireta. A dica lembra o aluno que, enquanto este estiver esperando em uma fila, isto é, quando estiver ocioso, pode utilizar o tempo para revisar, por exemplo, o léxico correspondente às mercadorias de um supermercado ${ }^{11}$. Essa dica, bem como as anteriores, sempre tem relação com os temas trabalhados na lição: são estratégias indiretas (b), metacognitivas (i), de organização e planejamento da aprendizagem (2).

\footnotetext{
${ }^{11} \mathrm{Na}$ lição 10, são trabalhados conceitos como fazer comprar, perguntar os preços, dizer o que se gosta ou não de comer e falar sobre receitas culinárias.
} 
A última dica do livro A1 não aparece nos capítulos, mas no anexo, composto por explicações gramaticais. Essa ocorrência (p. 255) também é a repetição de uma informação já fornecida anteriormente, a respeito da memorização da forma plural, junto com o vocábulo no singular. Essa dica, ao aparecer na sistematização das regras gramaticais, permite a sua aplicação e fixação dessa prática, que pode ser expandida para outros traços gramaticais.

Dicas de aprendizagem em Studio [21] A2 (FUNK; KUHN; WINZER-KIONTKE, 2015)

No segundo livro da série, de nível $A 2$, encontramos 14 dicas de aprendizagem. $A$ primeira delas (p. 32) representa a reiteração de uma estratégia do livro utilizada no nível anterior (Figura 2). Trata-se da aprendizagem dos vocábulos aos pares, mas, desta vez, são os membros masculino e feminino da família. Essa estratégia pode ser classificada, segundo a taxonomia de Oxford (1990), como estratégia direta (a), de memorização (i), de criação de relações mentais (1). A repetição da apresentação da estratégia possibilita que os estudantes a relembrem e reforcem o seu uso.

Outra dica (p. 148) é semelhante, mas apresenta um conteúdo mais gramatical. Ela sugere o uso de uma vogal específica (no caso, o acréscimo de um -e) quando o radical do verbo terminar com - $t$. Esse tipo de estratégia é classificado por Oxford como estratégia direta (a), cognitiva (ii), de exercício - repetição e ensaio de segmentos linguísticos (1), ou seja, reconhecimento e uso de fórmulas. Estratégias cognitivas semelhantes também aparecem com relação ao sufixo -ung (sempre feminino) e verbos que exigem sempre complemento dativo e acusativo.

Outras estratégias aparecem na parte final do livro, na revisão gramatical, na qual são expostas regras, explicações e tabelas gramaticais. Encontramos uma dica (p. 253) que incentiva a aprendizagem por meio da memorização "combinada", ou seja, dos verbos reflexivos juntamente com as preposições que os regem: estratégia direta (a), cognitiva (ii), de exercício - repetição e ensaio de segmentos linguísticos (1). Após, a estratégia (p. 254) apresentada se refere a fazer suposições, para descobrir o gênero de determinado substantivo através da declinação do adjetivo que o acompanha (por exemplo, a desinência es corresponde a um substantivo neutro). Esta estratégia é classificada, segundo Oxford, como estratégia direta (a), cognitiva (ii), de análise e raciocínio (3).

No livro A2, os autores apresentam pela primeira vez na Coleção uma estratégia direta (a), de compensação (iii) e de adivinhação inteligente (1). Essa se refere à formação das palavras, pois indica que seguidamente os substantivos terminados em -ung são formados por verbos e, por isso, o radical é o mesmo (p. 259). Acreditamos que a oferta desse tipo de estratégia é fundamental para a promoção da autonomia dos estudantes, pois possibilita que eles possam refletir sobre a língua sem o auxílio do professor, desenvolvendo a consciência metalinguística (CENOZ, 2013). Na mesma página, são apresentadas estratégias semelhantes: a primeira indica que o estudante deve prestar atenção no uso de verbos semanticamente 
semelhantes (porém com regências diferentes), que classificamos como estratégia direta (a), de memorização (i), de criação de relações mentais (1); a segunda é um lembrete de que, na conjugação dos verbos modais no Präteritum ${ }^{12}$, não há trema e um - $t$ deve ser sempre acrescentado: estratégia direta (a), cognitiva (i), de exercício, repetição e ensaio de segmentos linguísticos (1).

O Präteritum é o foco de outras dicas de aprendizagem (p. 260), por ser um tópico gramatical introduzido no nível A2. Ambas as estratégias são diretas e cognitivas, pois sinalizam aos estudantes que o Präteritum na segunda pessoa do singular e do plural é usado quase somente com os verbos modais ser/estar e ter (sein e haben) ${ }^{13}$ : estratégia de análise e raciocínio (3). A outra dica salienta aos alunos que os verbos cujo radical acaba em -t receberão obrigatoriamente um -e: estratégia direta (a), cognitiva (ii), de exercício reconhecimento e uso de fórmulas (1). Por fim, a última dica (p. 261) da seção e do livro relaciona o tempo verbal em foco ao Konjunktiv II (subjuntivo) e lembra sobre a construção gramatical das formas verbais polidas. Tal estratégia pode ser classificada, segundo Oxford (1990), como estratégia direta (a), cognitiva (ii), de exercício - reconhecimento e uso de fórmulas (1).

Dicas de aprendizagem em Studio [21] B1 (FUNK et al., 2015)

No livro B1, encontramos 15 dicas de aprendizagem. A primeira (p. 36) trata de uma comparação entre o Präteritum e o Konjunktiv // dos verbos modais. Essa lembra, como já referido en passant na dica apresentada no livro anterior, que os verbos que perderam o trema na forma do passado manterão a forma, mas terão o acréscimo do trema no conjuntivo (por exemplo, musste - müsste). Essa dica pode ser classificada, conforme a taxonomia de Oxford, como estratégia direta (a), de memorização (i), de criação de relações mentais (1). Esta dica se repete na página 242, quando a gramática é sistematizada.

A próxima ocorrência (p. 52) segue a lógica da dica apresentada na Figura 2 e pode ser classificada da mesma forma que a dica exemplificada acima. Entretanto, nesse caso, no livro didático, sugere-se usar a técnica de estudo de palavras em pares para memorizar adjetivos, juntamente com os seus respectivos antônimos, seguindo a lógica de associação semântica.

A outra dica de aprendizagem que encontramos (p. 129) acompanha uma simulação de prova de proficiência. No exercício em que o aluno deve escutar um programa de rádio e marcar quem disse cada sentença, a estratégia é um lembrete de que nem sempre as informações do áudio aparecem na ordem em que estão escritas no exercício. Podemos

\footnotetext{
${ }^{12}$ Präteritum é tempo verbal do passado simples. Em alemão, os verbos no Präteritum são utilizados, de modo geral, em situações de comunicação mais formais.

${ }^{13}$ Com os outros verbos, há o uso do Perfekt, outra forma verbal de carga semântica semelhante.
} 
classificar essa estratégia como indireta (b), metacognitiva (i) de centrar a aprendizagem (1). Essa é, portanto, uma das raras estratégias metacognitivas que encontramos na coleção.

Na página 169, a dica oferecida chama atenção à estrutura sintática e aos papéis semânticos de uma construção específica da língua alemã. Ao utilizar o verbo 'deixar' (lassen) junto com o infinitivo, o agente da sentença é o objeto, o sujeito é o paciente. Esse lembrete é bastante importante para falantes de português, porque muitas vezes não fazemos a diferenciação entre agente e paciente. Na frase, "Eu vou cortar o cabelo", na verdade o sujeito tem o cabelo cortado por outrem. Em alemão, usa-se ipsis litteris, que "deixamos alguém cortar o cabelo". Esta estratégia é direta (a), cognitiva (ii), de análise e raciocínio linguístico. Para compreender a diferença, os alunos precisam analisar os exemplos. Logo após, a dica ( $p$. 171) apresentada se refere à forma utilizada pelos pronomes relativos no caso genitivo conforme o seu gênero. A ocorrência se repete no panorama gramatical, que está disponível na parte final do livro. A estratégia utilizada é a direta (a), cognitiva (ii), de exercício reconhecimento e uso de fórmulas (1).

Finalmente, da mesma forma que nos livros anteriores, após as lições do livro, surge um panorama gramatical repleto de dicas de aprendizagem. Inicialmente, com duas dicas na página 236, há uma repetição de uma exposta no livro precedente: a estratégia direta (a), de compensação (iii), de adivinhação inteligente (1) é usada para que o aluno perceba que os substantivos terminados em - ung podem possuir uma forma verbal semelhante. Dessa forma, é possível que o aluno reforce a aplicação dessa estratégia durante o seu processo de aprendizagem. A seguinte, na mesma página, também é uma repetição, mas agora de conteúdo, não de estratégia. Formando uma palavra com três sufixos comuns de substantivos femininos (marcadas em diferentes cores), o quadro pretende facilitar a memorização do gênero de palavras femininas (Figura 3). A estratégia utilizada aqui é direta (a), de memorização (i), de uso de imagens e sons (2).

Figura 3 - Dica de memorização do gênero de palavras com sufixos

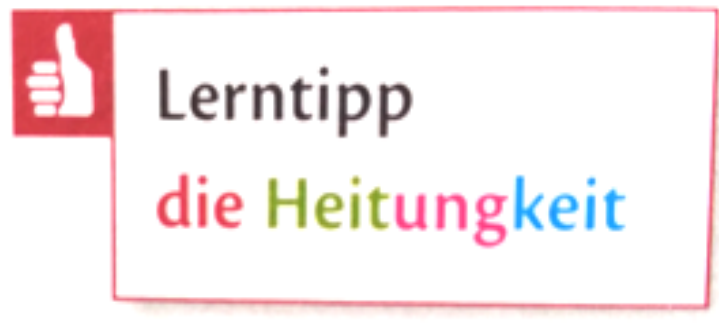

Fonte: Funk et al. $(2015, \text { p. 236) })^{14}$

Um tópico gramatical que gera bastante dúvidas entre os alunos aprendizes de alemão é a declinação dos adjetivos. Este é o foco das dicas apresentadas na página 239. A primeira,

\footnotetext{
${ }^{14}$ Tradução da Figura 3:

Dica de aprendizagem

die (artigo feminino) Heit-ung-keit: sufixos femininos
} 
de ordem mais demonstrativa, lembra que a declinação mais comum dos adjetivos é -en: estratégia direta (a), cognitiva (ii), de exercício - reconhecimento e uso de fórmulas (1); a seguinte revela o mesmo tópico já apresentado em outra dica (a respeito da identificação do gênero do substantivo através da declinação do adjetivo, p. 254 do livro A2), mas como uma nova estratégia: agora, usa-se o gênero do substantivo para declinar o adjetivo sem artigo: uma estratégia direta (a), cognitiva (ii), de análise e raciocínio (3).

Adiante, na página 241 , encontramos três dicas de aprendizagem sobre conjugação verbal. A primeira é a repetição da estratégia e do conteúdo da página 260 do livro A2. A segunda apresenta algo novo: ela sugere que as formas verbais irregulares devem ser memorizadas, mas oferece uma técnica para alcançar esse objetivo: repetições através do ritmo, correspondendo à estratégia direta (a), de memorização (i), de uso de imagens e sons (2), de Oxford. A terceira dica lembra que os verbos auxiliares sein e haben (ser/estar e ter) são utilizados no Plusquamperfekt (pretérito-mais-que-perfeito) segundo o mesmo princípio do uso no Perfekt, ou seja, utilizando o mesmo verbo auxiliar. A estratégia também é de uso de imagem e sons porque os autores se valem de uma frase que possui rima: Haben und sein setzt man wie beim Perfekt ein!

Portanto, as dicas de aprendizagem distribuem-se ao longo de toda a coleção. Ao destacar esse tipo de estratégia, os autores facilitam o seu reconhecimento e, consequentemente, fomentam um envolvimento autodirigido e ativo dos estudantes e a transferência de estratégias entre diferentes contextos e línguas (cf. OXFORD, 1990).

\subsection{Minimemos}

Outra forma de apresentação de estratégias de aprendizagem na coleção Studio [21] é por meio dos chamados Minimemos. Nesses pequenos quadros, como no exemplo abaixo, encontramos informações importantes apresentadas de forma sistematizada para serem memorizadas mais facilmente.

Figura 4 - Minimemo sobre abreviaturas de medidas

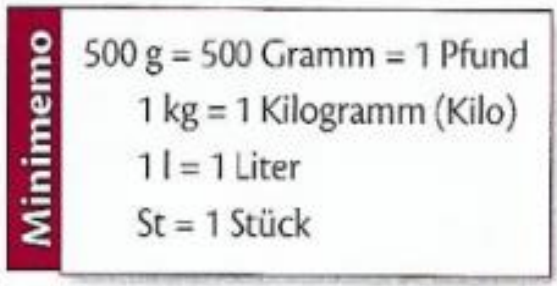

Fonte: Funk, Kuhn e Winzer-Kiontke (2015, p. 188) $)^{15}$

${ }^{15}$ Tradução da Figura 4:

Minilembrete

$500 \mathrm{~g}=500$ gramas $=$ meio quilo

$1 \mathrm{~kg}=1$ quilograma (quilo) 
Em todos os livros da coleção, os apontamentos não oferecem explicação (embora, muitas vezes, exemplifiquem alguma estrutura ou formação gramatical), mas reforçam particularidades da língua que têm relação com a lição que está sendo trabalhada e precisam ser memorizadas, para o uso da língua em situações de comunicação específicas em algum país germanófono. Podemos classificar todos esses lembretes, conforme Oxford (1990), como estratégias diretas (a), de memorização (i), de revisão (3). Reiteramos que tais ocorrências apresentadas nos livros didáticos somente poderão se tornar estratégias se forem assumidas pelos alunos como tal, ou seja, se chegarem ao nível da metacognição (cf. FLAVELL, 1979). Dessa forma, podem contribuir para a promoção da autonomia e da autoconfiança dos estudantes (BIMMEL; RAMPILLON, 2000; OXFORD, 1990; TEN KATHEN, 2016). Por isso, a abordagem de uso dos Minimemos em sala de aula pode alterar sua classificação.

Como podemos verificar na tabela 1, a ocorrência de Minimemos diminui à medida em que o nível linguístico dos livros aumenta. Temos duas hipóteses de interpretação para essa redução. Em primeiro lugar, a informação que foi abordada no nível A1 ainda vale linguisticamente para os outros níveis e não necessita ser repetida, como, por exemplo, o Minimemo representado na Figura 5, no qual se apresenta a formação dos números múltiplos de 10 (30 a 90) e se destacam as exceções. Não é necessário retomar essa regra com os níveis superiores, pois sempre que os números cardinais forem utilizados, não importando o contexto, terão a mesma forma.

Figura 5 - Minimemo: representação da formação dos números múltiplos de 10

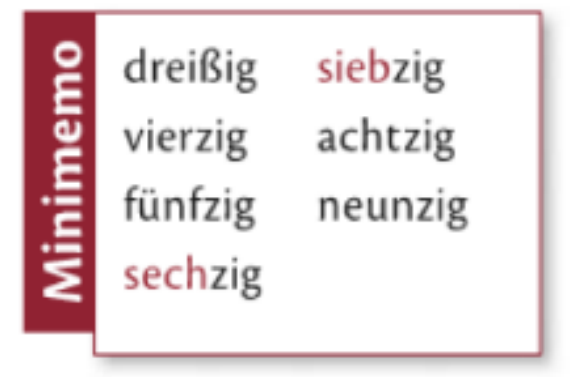

Funk e Kuhn (2013, p. 20)

Além disso, no início do estudo de uma nova língua, aprendemos noções linguísticas elementares em grande quantidade. No livro A1 (FUNK; KUHN, 2013), por exemplo, alguns desses aspectos são: conjugação verbal no presente do verbo sein - ser/estar (p. 19), gênero das partes do dia (p. 94), contração de preposições com artigos (p. 111), principais preposições em contexto temporal (p. 92-94), entre outros. Conforme avançamos,

$1 \mid=1$ litro

St $[$ Stück] = 1 porção/bocado/fatia 
trabalhamos com estruturas linguísticas mais detalhadas e complexas, que seriam mais difíceis de representar em um (mini-)quadro de lembrete.

\section{Sistematização}

As estratégias de aprendizagem também são expostas na coleção de livros didáticos em análise na "sistematização", que aparece frequentemente acompanhando a já mencionada Lerntipp. Embora haja esta conexão óbvia com a Lerntipp, estas estratégias são mais elaboradas: não apenas a informação principal, mas também os procedimentos atrelados à aplicação da estratégia são abordados. No exemplo mostrado na Figura 2 (p. 34), a dica/Lerntipp sugere que os substantivos em alemão devam ser memorizados juntamente com seus respectivos artigos, já que estes são, muitas vezes, diferentes em outras línguas. A sistematização sugere uma técnica mnemônica, em que dois substantivos aleatórios (mas com o mesmo artigo) devem ser imaginados juntos. É, segundo Oxford, uma estratégia direta (a), de memorização (i), de uso de imagens e sons (2).

No exemplo seguinte (p. 79), ainda no livro A1, é apresentada outra técnica para a aprendizagem específica de vocabulário. O estudante deve etiquetar móveis ou outros objetos da casa com seus respectivos nomes em alemão. Acrescido a isto, a proposta ensina como marcar no próprio vocábulo a sílaba tônica, artigo e forma plural e ainda sugere o registro de uma frase com o uso do vocábulo. A técnica mostra o procedimento com uma figura ilustrativa juntamente com cinco Lerntipps. Segundo Oxford (1990), essa sistematização pode ser classificada como uma estratégia direta (a), de memorização (i), de emprego de ações (4).

No livro $A 2$, encontramos novamente um exemplo dessa sistematização. Na página 163 , há três Lerntipps, juntamente com exercícios para treinar efetivamente as estratégias. Todas podem ser categorizadas como estratégia direta (a), de memorização (i), de criação de relações mentais (1). A primeira se refere a Wortfelder (campos semânticos): ao aluno é incentivado, depois da apresentação de exemplos, fazer conexões entre vocábulos partindo de um tema. As palavras relacionadas devem ser aprendidas em conjunto. A próxima dica de estratégia é de classificação, semelhante à anterior: sugere a construção de uma família de palavras (Wortfamilie). A reunião não é necessariamente por tema, mas por um radical comum. As palavras que possuem este radical na sua formação devem ser listadas e agrupadas. A última incentiva o aluno a memorizar os substantivos já conectados com os verbos que são mais frequentemente usados nesta associação.

No livro B1, encontramos dois exemplos semelhantes desta sistematização. Tanto na página 18 , quanto na 197 , há a sugestão de confeccionar cartões. Nestes cartões (cuja a própria produção já representa uma forma de estudo), estarão informações referentes aos temas específicos abordados nas lições. Na página 18, há a sugestão da aprendizagem dos verbos irregulares em alemão, para o aluno escrever não apenas suas formas (infinitivo, 
Präteritum e Perfekt), mas também exemplos das formas conjugadas; em seguida, recomenda-se a leitura em voz alta para a memorização através do ritmo, bem como fazê-la usando um movimento específico para cada tempo verbal, associando som e movimento. $\mathrm{Na}$ página 197, as palavras selecionadas (de um texto específico da lição) podem ser anotadas num cartão e em seu verso acompanhada de uma descrição gramatical (classe, sinônimos, antônimos etc.) e de exemplos de uso em diferentes contextos. Temos, então, no livro B1, uma combinação de estratégias diretas (a), de memorização: primeiramente de criação de relações mentais (1), mas também de uso de imagens e sons (2) - uso do ritmo e de movimentos, e, por fim, de revisão (3), quando os cartões serão utilizados para o estudo.

Essa sistematização é importante, porque possibilita que o aluno coloque em prática as estratégias apresentadas nos livros didáticos. Para Oxford (1990), esse treino é fundamental, e a abordagem deve ajudar cada estudante a ganhar autoconfiança com relação a como ele aprende bem como desenvolver meios de potencializar as suas experiências de aprendizagem.

\section{Autoavaliação}

Outra estratégia essencial que os livros apresentam são os testes de autoavaliação do processo de aprendizagem e autoconhecimento, nos quais o aluno deve avaliar autonomamente o que já sabe e o que ainda precisa aprender. Esse "controle" sobre a aprendizagem é fortemente sugerido pelo Conselho da Europa (2005), pois quando os alunos, através da administração do que já dominam, ou não, estão conscientes do seu aprendizado, podem, consequentemente, descobrir a melhor forma de aprender uma nova língua.

A maioria das estratégias avaliativas aparecem de forma padronizada na coleção Studio [21]. Sempre, ao final de cada lição, há uma proposta de avaliação de aprendizagem. Observando a Figura 5 (ver abaixo), percebem-se os principais elementos da autoavaliação: o título da atividade já denuncia seu objetivo fundamental: Fit für Einheit 2? Testen Sie sich! (Pronto para a lição 2? Teste-se!). Com base em Oxford (1990), pode-se dizer que essa atividade poderia ser categorizada como estratégia indireta (b), metacognitiva (i), de avaliação da aprendizagem. O exercício objetiva que o aluno monitore o progresso de sua aprendizagem. Através da avaliação pormenorizada, o aprendiz pode analisar exatamente onde não alcançou um desenvolvimento satisfatório e, com o auxílio dessa ferramenta, aprimorar, de forma autônoma, a aprendizagem. 
Figura 5 - Exemplo de autoavaliação, disponibilizada no fim de cada lição Fit für Einheit 2? Testen Sie sich!

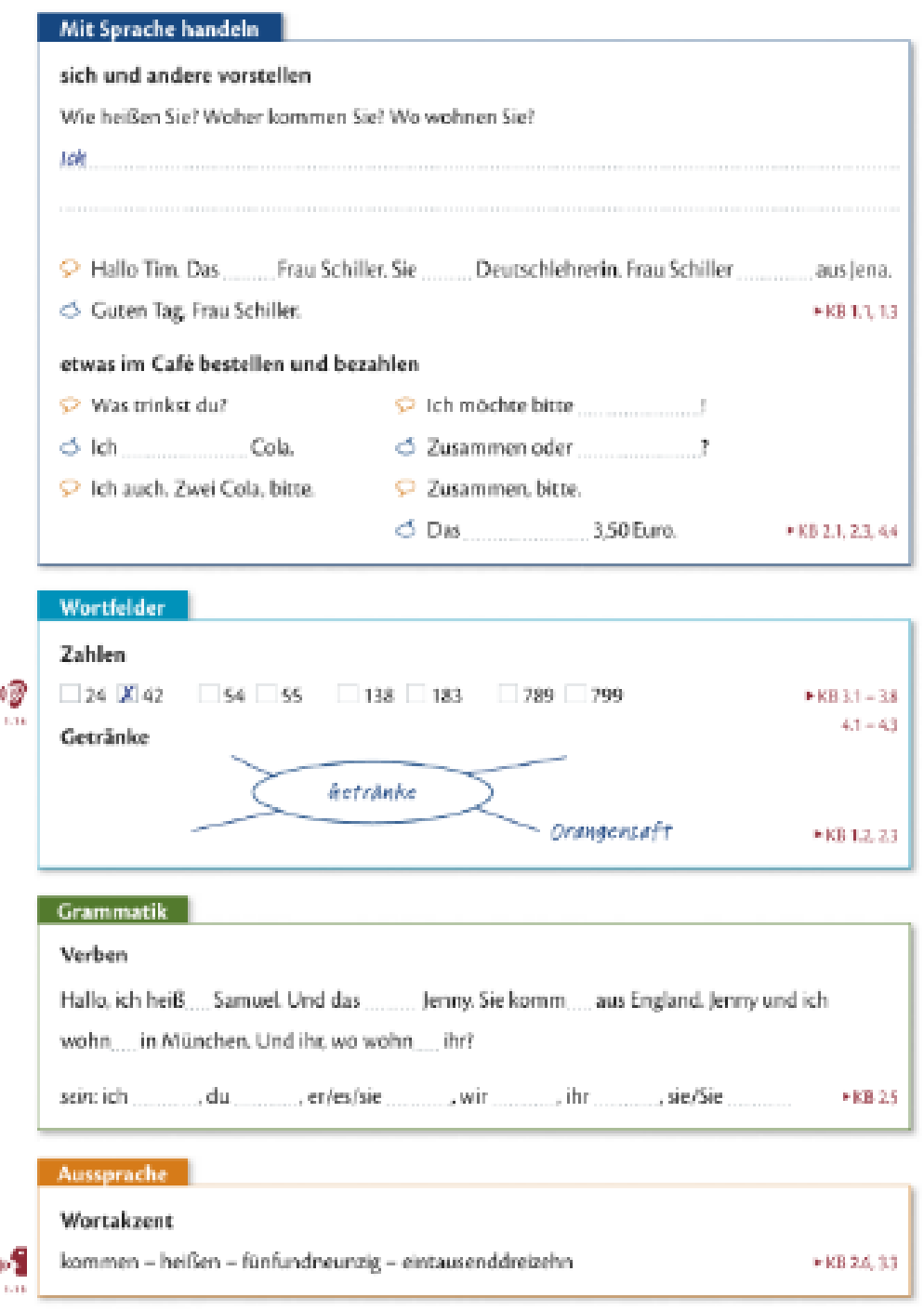

Fonte: Funk e Kuhn (2013, p. 31)

A autoavaliação é dividida normalmente em categorias, como no exemplo: Mit Sprache handeln (lidando com a língua), Wortfelder (campos semânticos), Grammatik (gramática) e Aussprache (pronúncia). No exemplo apresentado na Figura 5, primeiramente, o aluno é incentivado a "apresentar a si e ao outro", a completar as lacunas e a revisar como "pedir algo num café e pagar". Nos campos semânticos, o vocabulário utilizado na lição deve ser listado. No terceiro campo, é testado o conteúdo gramatical abordado na lição. Ao fim de algumas lições, nas quais há ênfase na pronúncia, o aprendiz pode conferir as vogais ou consoantes enfocadas na lição. Ao lado de cada campo, há a indicação da página e dos itens nos quais o tema foi abordado, ou seja, o estudante pode confirmar sozinho suas hipóteses ou ainda revisar o que não foi fixado. 
Além desses componentes uniformizados, os livros da coleção também oferecem quatro vezes atividades de autoavaliação dentro de determinadas lições. No livro A1 (p. 125), há uma questão autoavaliativa na segunda Station para os exercícios das lições 4,5 e 6 . 0 aluno deve marcar o que ele consegue fazer bem ou não tão bem em alemão (como por exemplo: eu consigo... descrever uma casa; ... citar oito móveis; ...dizer as horas; ...).

Figura 6 - Atividade de autoavaliação dentro de uma lição no livro A1

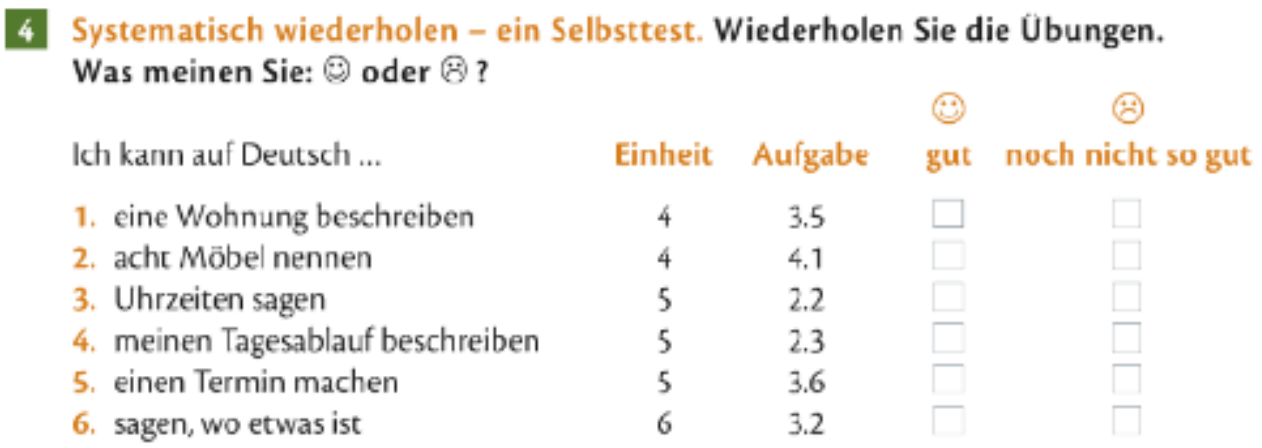

Fonte: Funk e Kuhn (2013, p. 125) ${ }^{16}$

No livro A2, o tipo de autoavalição é bem diferente dos apresentados anteriormente: o que se avalia não é o conteúdo aprendido, mas os processos de aprendizagem mais efetivos para cada aluno. No primeiro exercício (p. 163), o aprendiz deve avaliar algumas afirmações a respeito da aprendizagem em três diferentes colunas: "ajuda", "não ajuda", "ainda não fiz". As afirmações sugerem técnicas que podem converter-se em estratégias de aprendizagem, caso sejam conscientemente utilizadas pelo aprendiz, como: a leitura de textos em voz alta; a busca de informações na internet; a aprendizagem em grupo, entre outras. Podemos denominar este tipo de estratégia, segundo Oxford, de indireta (b), metacognitiva (i), de organização e planejamento (2). A segunda atividade, que também pode ser categorizada dessa forma, incentiva o aluno a refletir sobre a maneira que aprende melhor. Como podemos visualizar na Figura 7, o estudante deve marcar as alternativas que mais caracterizam o seu modo de aprendizagem: Como? Sentado, em pé, deitado, movimentando-se; Quando? Pela manhã, ao meio dia, à tarde, à noite; Com quem? Com o quê? ... Onde? ... Posteriormente, a

\footnotetext{
${ }^{16}$ Tradução da Figura 6:
}

Revisão sistemática - um autoteste. Revise os exercícios.

O que você acha? (:)ou (i)?

Eu consigo em alemão...

1. descrever uma moradia

2. nomear oito móveis

3. dizer as horas

4. descrever a minha rotina

5. marcar um compromisso

6. dizer onde se está 
fim de refletir sobre os resultados, os alunos podem fazer uma tabela das formas preferidas no curso.

Figura 7 - Atividade de autoavaliação dentro de uma lição no livro A2

2 Hier lerne ich gern ... Wie und wann lernen Sie am besten? Kreuzen Sie an und vergleichen Sie.
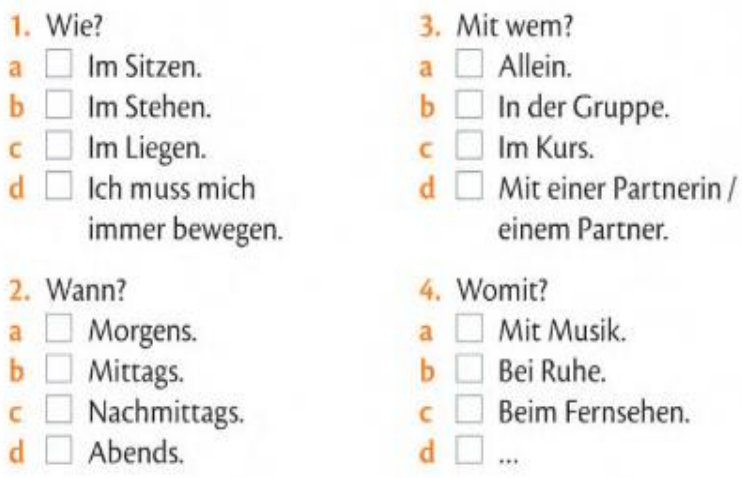

Nachdenken über das Lernen
\begin{tabular}{|l|l|l|l|l|}
\hline Kursstatistik & \multicolumn{1}{|l|}{} \\
\hline & a & b & c & d \\
\hline Wie? & II & I & I & III \\
\hline Wann? & III & II & & \\
\hline Mit wem? & & & & \\
\hline Womit? & & & & \\
\hline Wo? & & & & \\
\hline
\end{tabular}

Fonte: Funk, Kuhn e Winzer-Kiontke (2015, p. 175 $)^{17}$

No livro B1 (p. 207), a questão apresentada é da mesma natureza do livro A1 (Figura 6 , p. 125). A única modificação é em relação às lições $(6,7,8,9$ e 10) e aos conteúdos abordados (como, por exemplo: eu consigo... falar sobre o tempo; ... falar sobre o personagem de um romance; ... descrever instituições europeias, entre outras).

Produção oral: Redemittel

Os Redemittel (estruturas prontas para a produção oral) aparecem com grande frequência nos livros Studio [21]. São quadros (vide exemplo abaixo, Figura 8), semelhantes aos já abordados Minimemos ou Lerntipps, com opções de estruturas prontas usadas frequentemente na produção. Como podemos verificar na tabela acima, há cerca de 20 ocorrências em cada livro didático.

\footnotetext{
${ }^{17}$ Tradução da Figura 7:

2. Aqui/Dessa forma eu gosto de aprender... Como e quando você aprende melhor? Marque e compare.
} 
Figura 8 - Exemplo de quadro com Redemittel no livro A1
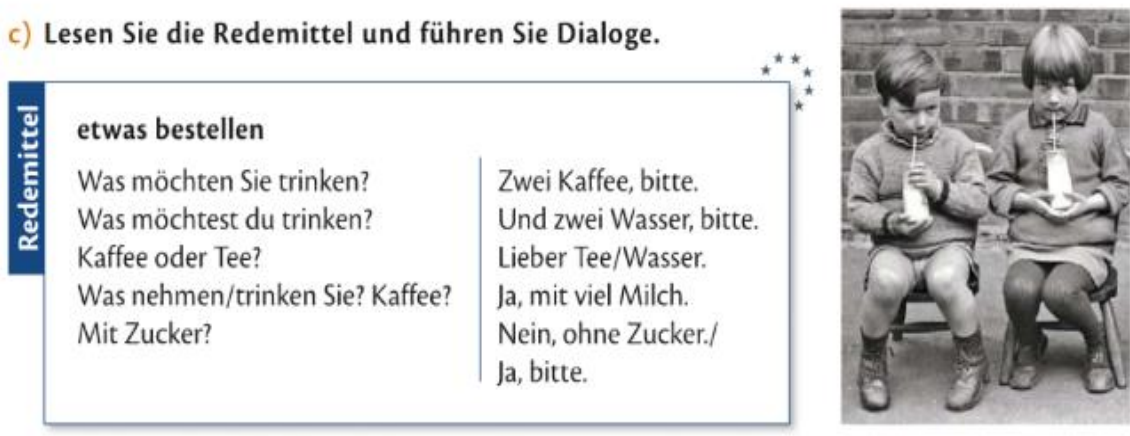

Fonte: Funk e Kuhn (2013, p. 19)

A estratégia explorada pela exposição das estruturas é, conforme a taxonomia de Oxford (1990), direta (a), cognitiva (ii), de exercício (1). A prática de apresentação das estruturas mantém-se até o nível mais avançado da coleção, ou seja, inclusive as estruturas mais complexas são apresentadas. Essa prática possibilita que o estudante possa utilizar os quadros de Redemittel para guiar-se na comunicação e formar um diálogo mais bem estruturado.

\section{Produção escrita}

Da mesma forma que o livro se dedica especificamente à comunicação oral, também há estratégias voltadas para a produção escrita. As estratégias diretas (a), cognitivas (ii), de recepção e envio de mensagens (2) e de análise e raciocínio (3), segundo a classificação de Oxford, contemplam estratégias para aprimorar a habilidade da produção escrita. No livro A1 (p. 153), encontramos um exercício que explica passo a passo como escrever um cartão postal, desde o planejamento, a organização de informações e a posterior correção e reescritura. No livro B1 (p. 149), também há uma espécie de guia, indicando aos alunos como escrever uma história simples. Perguntas chave devem orientar a escrita: quem? O quê? Quando? Como? Ao responder as questões o aluno confirma que o texto contém todas as informações necessárias.

Além de apresentar guias e esquemas que facilitam a expressão escrita, o que os Redemittel representam para a comunicação oral, o quadro Textbausteine (elementos de construção textual) faz para a composição escrita. Esse quadro específico aparece somente no livro B1, o que é compreensível, já que a habilidade escrita mais formal se desenvolve mais tardiamente na aprendizagem da língua. Os Textbausteine oferecem um tema relacionado à

\footnotetext{
${ }^{18}$ Tradução da Figura 8:

Leia as frases prontas e conduza diálogos

Pedir algo

O que o sr./a sra. gostaria de pedir?
}

Dois cafés, por favor. 
lição juntamente com opções de frases mais comuns relacionadas ao assunto. Podemos ver na Figura 9 o exemplo da página 70 do livro B1, no qual os alunos estruturam os textos usando as sugestões de frases oferecidas pelo Textbausteine:

Figura 9 - Exemplo de estruturas para a construção de textos

b) Schreiben Sie einen kurzen Bericht. Die Textbausteine helfen.

eine Region / einen Ort vorstellen

Ich möchte über eine Region/Gegend/Stadt in/aus meinem Land berichten: ...

Damals/Früher gab es dort ... / Man fand/entdeckte ...

In der Region / Dort arbeiteten und lebten ... (Millionen) Menschen. Die Region hatte ...

Einwohner. Heute leben dort ... / Jetzt gibt es ... / Besonders bekannt ist die Region für ...

Fonte: Funk e Kuhn (2015, p. 70) $)^{19}$

Consideramos esse tipo de ocorrência uma estratégia de aprendizagem muito eficiente, pois o aluno, seguindo conscientemente os passos apresentados, poderá adquirir, depois de algum tempo, a habilidade de realizar a tarefa com mais facilidade e autonomia.

\section{Conclusão}

Os resultados deste estudo mostram que um dos pilares da coleção Studio [21] é a apresentação de estratégias de aprendizagem e o trabalho com elas. Ao longo de toda a coleção, há ocorrências de apresentação de estratégias de aprendizagem, muitas vezes destacadas dos textos e exercícios, mas sempre integradas à temática abordada na lição. Entretanto, há predomínio de estratégias diretas, especialmente de memorização e cognitivas. Dessa forma, são priorizadas estratégias sobre a língua em si em detrimento das estratégias indiretas (metacognitivas, sociais e afetivas), aquelas que não têm relação direta com a língua-alvo, mas com aspectos psicológicos e sociais da aprendizagem. Encontramos quatro tipos de ocorrências de estratégias indiretas ao longo de toda a coleção, mas as estratégias de autoavaliação, a exemplo da Figura 5, repetem-se depois de cada lição. Esses resultados assemelham-se aos que Cunha (2013) encontrou na coleção precursora do livro Studio [21]. A coleção cumpre, portanto, o que propõe (conforme Funk et al., 2016), mas com limitações relacionadas à distribuição do tipo de estratégias nos livros didáticos.

\footnotetext{
${ }^{19}$ Tradução da figura 9:
}

Escreva um pequeno relato. Os elementos de produção textual ajudam.

Apresentar uma região/ um local

Eu gostaria de falar sobre uma região/área/cidade do meu país...

Naquela época/antigamente existia lá...Nós encontrávamos/descobríamos...

Na região/Lá trabalhavam e viviam...(milhões) de pessoas. A região tinha... habitantes. Hoje moram lá.../ Agora existe.../ A região é especialmente conhecida por... 
Para que as estratégias apresentadas pelos livros didáticos sejam efetivamente adotadas pelos estudantes, é necessário que sejam exercitadas, pois precisam atingir, muitas vezes, o nível da metacognição. É essencial que as estratégias estejam inseridas em livros didáticos, como no livro Studio [21]. Segundo Vilaça (2010), uma das vantagens da inclusão de estratégias nos materiais é a sua maior integração às atividades e tarefas pedagógicas. Isso permite maior possibilidade de contextualização e assimilação das mesmas.

Como vimos na fundamentação teórica, a investigação de estratégias de aprendizagem de DaF ainda é incipiente (CARVALHO, 2016; CUNHA, 2013; STANKE, 2008; TEN KATHEN, 2016). Por isso, é necessário conduzir outras pesquisas, envolvendo a participação de estudantes. Nesse aspecto, a presente pesquisa se demonstra-se limitada. Acreditamos que uma futura pesquisa deva investigar o uso efetivo pelos estudantes das estratégias oferecidas pelo livro didático. A oferta de dicas de aprendizagem, por exemplo, não é garantia da sua adoção pelos alunos.

Acreditamos que a contribuição deste estudo reside na reflexão sobre estratégias de aprendizagem e prática de análise de livros didáticos. Consequentemente, visamos ao aprimoramento e à expansão do repertório e do uso de estratégias por nossos alunos. Por extensão, o estudo pode contribuir para atingir os mesmos objetivos de outros professores. Ao utilizar-se de mais estratégias de aprendizagem, que estão de acordo com o estilo cognitivo de cada estudante, provavelmente o aluno pode atingir mais facilmente o seu objetivo. Além disso, conforme estudos de Bimmel e Rampillon (2004) e Ten Kathen (2016), o ensino de estratégias também pode contribuir para que cada estudante se sinta representado na aula, pois elas podem ser um importante recurso para promover a diferenciação e o desenvolvimento da autonomia.

\section{Referências}

BIMMEL, P.; RAMPILLON, U. Lernautonomie und Lernstrategien. Fernstudieneinheit 23. Goethe Institut, München: Langenscheidt, 2004.

CARVALHO, M. C. D. O ensino de estratégias de aprendizagem e o desenvolvimento da autonomia do aprendiz de alemão em turmas multisseriadas de escolas públicas do Estado de São Paulo. 2016. 157 f. Dissertação (Mestrado em Língua e Literatura Alemã) - Faculdade de Filosofia, Letras e Ciências Humanas, Universidade de São Paulo. São Paulo: 2016. https://doi.org/10.11606/D.8.2016.tde-15082016-092837

CENOZ, J. The influence of bilingualism on third language acquisition: Focus on multilingualism. Language Teaching, v. 46, n. 1, p. 71-86, jan. 2013.

https://doi.org/10.1017/S0261444811000218

CONSELHO DA EUROPA. Quadro Europeu Comum de Referência para Línguas. Porto: Asa Editores, 2005. 
CUNHA, M. C. C. Análise de estratégias de ensino/aprendizagem em materiais didáticos de alemão como língua estrangeira: perspectivas pós-comunicativas em contraste. 2013. $132 \mathrm{f}$. Dissertação (Mestrado em Língua e Literatura Alemã) - Faculdade de Filosofia, Letras e Ciências Humanas, Universidade de São Paulo. São Paulo: 2013. https://doi.org/10.11606/D.8.2013.tde-28082013-123941

ELLIS, R. The Study of Second Language Acquisition. Oxford: Oxford University Press, 1994.

FLAVELL, J. H. Metacognition and Cognitive Monitoring: A New Area of CognitiveDevelopmental Inquiry. American Psychologist, v. 34, n. 10, p. 906-911, 1979. https://doi.org/10.1037//0003-066X.34.10.906

FUNK, H. et al. Studio [21]: Unterrichtsvorbereitung Deutsch als Fremdsprache A1. Berlin: Cornelsen, 2013.

FUNK, H.; KUHN, C. Studio [21]: Das Deutschbuch A1. Berlin: Cornelsen, 2013.

FUNK, H; KUHN, C; NIELSEN, L; WINZER-KIONTKE, B. Studio [21]: das Deutschbuch B1. Berlin: Cornelsen, 2015.

FUNK, H; KUHN, C; WINZER-KIONTKE, B. Studio [21]: das Deutschbuch A2. Berlin: Cornelsen, 2015.

GLABONIAT, M. et al. Profile Deutsch: Gemeinsamer Europäischer Referenzrahmen. Berlin/München: Langenscheidt, 2005.

GROSJEAN, F. Bilingual: life and reality. Cambridge: Harvard Univ., 2010. https://doi.org/10.4159/9780674056459

HERDINA, P.; JESSNER, U. A. Dynamic Model of Multilingualism: Perspectives of Change in Psycholinguistics. Clevedon/Buffalo/Toronto/Sydney: Multilingual Matters, 2002. https://doi.org/10.21832/9781853595547

HUFEISEN, B. L1, L2, L3, L4, LX - alle gleich? Linguistische, lernerinterne und lernerexterne Faktoren in Modellen zum multiplen Spracherwerb. Zeitschrift für Interkulturellen Fremdsprachenunterricht, v. 8, n. 2/3, p. 97-109, 2003.

MACEDONIA, M. Three Good Reasons Why Foreign Language Instructors Need Neuroscience. Journal of Studies in Education, v. 3, n. 4, p. 1, 2013.

https://doi.org/10.5296/jse.v3i4.4168

OXFORD, R. L. Language learning strategies: what every teacher should know. Boston: Heinle \& Heinle, 1990.

OXFORD, R. L. Language learning styles and strategies: an overview. Learning Styles \& Strategies. GALA, p. 1-25, 2003. https://doi.org/10.1515/iral.2003.012

PAIVA, V. L. M. O. Estratégias de Aprendizagem de Línguas Estrangeiras. In: XI Semana de Estudos Germânicos, 1996. ANAIS... Belo Horizonte, 1996. p. 32-40.

PARADIS, J.; GENESEE, F.; CRAGO, M. B. Dual language development and disorders: a handbook on bilingualism and second language learning. 2. ed. Baltimore: Brookes, 2011.

PEYER, E.; KAISER, I.; BERTHELE, R. The multilingual reader: advantages in understanding and decoding German sentence structure when reading German as an L3. International Journal of Multilingualism, v. 7, n. 3, p. 225-239, 2010.

https://doi.org/10.1080/14790711003599443 
PRAT, C. S.; JUST, M. A. Brain Bases of Individual Differences in Cognition. Psychological Science Agenda, n. May, p. 1-6, 2008. https://doi.org/10.1037/e553882011-002

RUBIN, Joan. What the "Good Language Learner" can teach us. TESOL Quarterly, v. 9, n.1, p. 41-51, 1975. https://doi.org/10.2307/3586011

STANKE, R. C. S. F. O ensino do alemão para o fim específico da leitura: conscientização, estratégias, compreensão. 160 f. Dissertação (Mestrado em Linguística Aplicada) - Faculdade de Letras, Universidade Federal do Rio de Janeiro. Rio de Janeiro, 2008.

TEN KATHEN, C. L. Estratégias de aprendizagem no ensino individualizado em alemão como língua estrangeira em uma escola bilíngue teuto-brasileira. 138 f. Dissertação (Mestrado em Língua e Literatura Alemã) - Faculdade de Filosofia, Letras e Ciências Humanas, Universidade de São Paulo. São Paulo, 2016. https://doi.org/10.11606/D.8.2017.tde-14032017-144855

VILAÇA, M. L. C. A importância de pesquisas em estratégias de aprendizagem no ensino de línguas estrangeiras. Cadernos do CNLF (CiFEFil), v. 15, p. 208-220, 2010.

Recebido em: 20/09/2018

Aceito em: 18/02/2019 